\section{INTERNAL FIXATION DEVICES FOR REPAIR OF FEMORAL FRACTURE IN LION-TAILED MACAQUE (MACACA SILENUS)}

\author{
G.L. Ghosh, J.C. Paul, A. Biswas, S.K. Nandi ${ }^{1}$ and P.K. Bose \\ Zoological Garden, Alipore, Kolkata, West Bengal, India.
}

Wild animals, like domestic animals, are prone to accidents such as road collision, falls, drowning, fires which might lead to death. Although animals with bone fractures are very rarely noticed in the wild because only a negligible portion suffer from such accidents. Femoral shaft fracture is commonly seen in dog and cat and in almost every instance, surgical intervention is required (Leighton, 1994). This communication describes the successful management of femoral shaft fracture in a Lion-tailed Macaque.

\section{Case history}

A Lion-tailed Macaque about nine years old was found in complete recumbency in Zoological Garden, Alipore, Kolkata. The animal struggled hard to stand but could not, was panting heavily and salivating. On closer observation, it was found that the right hind leg of the animal was in a stretched position. Simple manipulations revealed that there was a complete closed fracture of femur (in distal third shaft region). There was a crepitus and pain on manipulation. Abnormal movement of the fracture end of femur was also noticed.

Pre-operatively, the animal was administered with a nonsteriodal anti-inflammatory drug, Phenyl butazone 400mg intramuscularly. Surgical operation was undertaken after the regression of initial inflammatory phase (2-4 days).

\section{$\underline{\text { Surgical procedure }}$}

Before the surgery, the animal was kept off-feed for 12 hours and water for six hours. The animal was sifted in the squeeze cage and was premedicated with atropine sulphate @ $0.04 \mathrm{mg}$ / $\mathrm{kg}$ body weight subcutaneously. The Lion-tailed Macaque was then given medatomidine @ $10 \mu \mathrm{g} / \mathrm{kg}$ body weight and ketamine hydrochloride anaesthesia @ 7mg/kg body weight intramuscularly. After aseptic preparation, the femur was approached laterally by a cranio-lateral incision through the skin and subcutaneous tissues directly over the area of contact between fascia lata and the cranial edge of the biceps femoris (Fig. 1). The exposed fasia lata was incised along the same line (Fig. 2). A single steinmann pin of appropriate size was introduced into the medullary cavity of the stabilized proximal fragment in a retrograde manner to emerge in the trochanteric fossa. During the insertion of the pin into the proximal fragment, the hip joint was kept slightly extended in a caudal direction and the femoral shaft held parallel to the table top to prevent impingement of sciatic nerve. The pin then penetrated the skin medial to the trochanteric fossa (Fig. 3). The chuck was removed and placed on the proximal end of the pin and used to withdraw the pin until just the tip protruded from the proximal fragment of the fracture site. The fracture was now reduced and the pin then inserted into the distal medullary canal. After seating of the pin, the reduction and stability was assessed by manual rotation of the distal fragment. The protruding pin was cut with a pin cutter to remove the trocar point. Closure was accomplished by suturing the incisions in the fascia lata, subcutaneous tissues and skin in the usual manner.

\section{Post-operative care}

Post-operatively, the animal was administered injection cefotaxime sodium $1 \mathrm{~g}$ intramuscularly twice daily for seven days to avoid any post-operative infection, and with phenyl butazone 400mg for three days. The animal was restricted to less exercise for 12 days and thereafter, progress was satisfactory and a gradual return to full function was advised. Dressing of wound was done on fourth and seventh post-operative days and stitches were removed on the tenth day.

Good weight-bearing was observed in the immediate postoperative period indicated that the fracture fixation was good. The animal showed gradual improvement in weight bearing and functional recovery of the limb. Good fixation was maintained up to sixth week suggesting that single pin fixation as per the method of Whittick (1990) can provide rigid fixation.

Radiological signs of fracture healing were evident as early as on day 21 by periosteal reaction and mild callus formation (Fig4). At day 45, healing was complete. No signs of osteomyelitis or any other abnormal change was noticed. The intramedullary pin was removed 45 days post-operatively after ensuring supporting function of the injured limb.

\section{Acknowledgement}

The authors are thankful to Sri. Adhir Das, Director, Alipore Zoological Garden, Kolkata for the facilities provided and given permission for preparing the article.

\section{References}

Leighton, R.L. (1994). Small Animal Orthopedics. Wolfe publishing. London.

Whittick, W.G. (1990). Canine Orthopedics. $2^{\text {nd }}$ edition. Lea and Febiger. Philadelphia. London. 


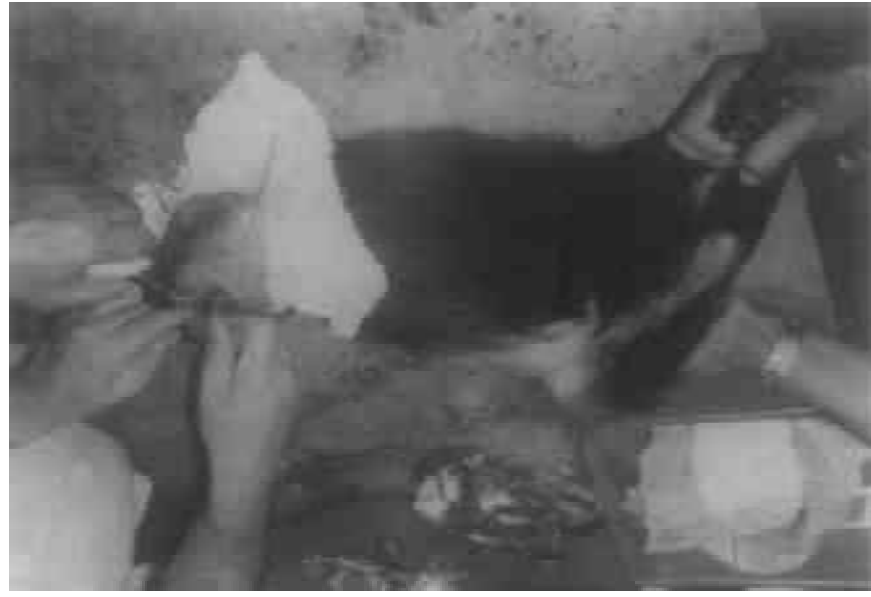

Fig. 1. Photo showing incision of skin and subcutaneous tissue between fascia lata and biceps femoris

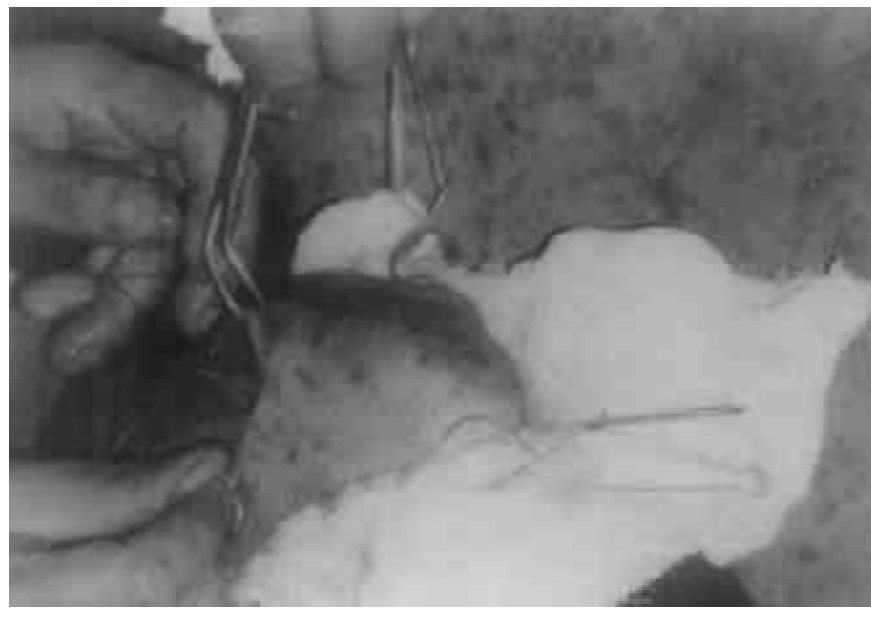

Fig. 3. Intramedullary pin penetrated the skin to the trochanteric fossa

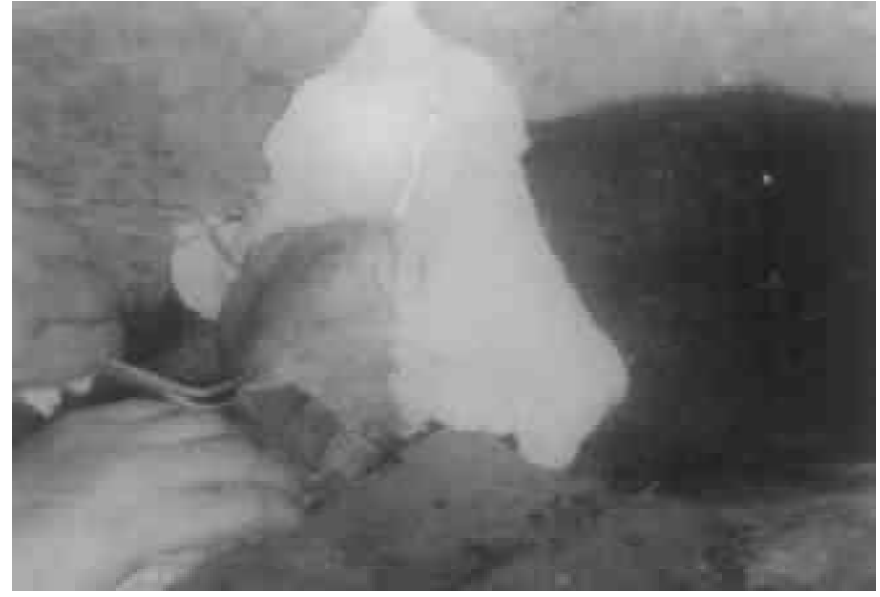

Fig. 2. Exposed fascia lata

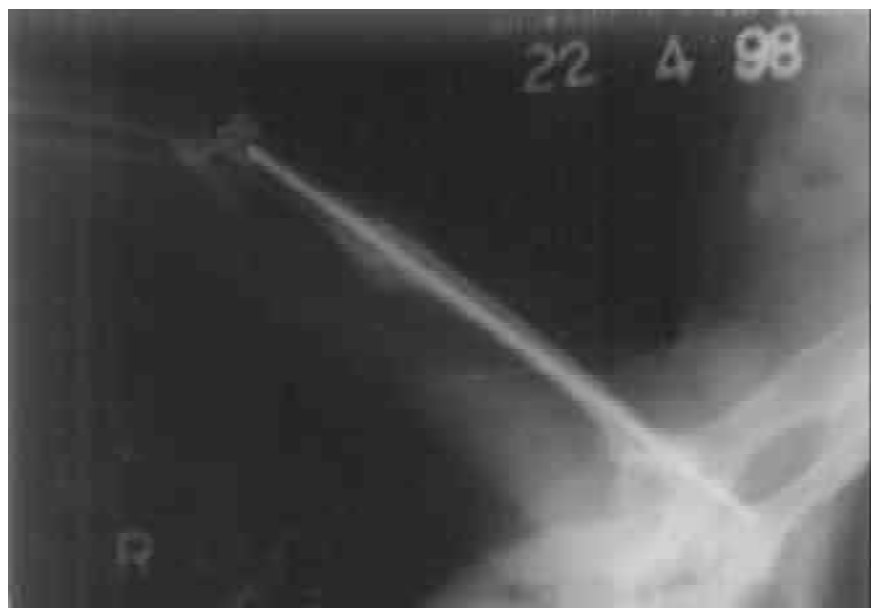

Fig. 4. Skiagram showing periosteal reaction and callus formation at the fractured site 